Research Article

\title{
Multiobjective Economic Optimal Dispatch for the Island Isolated Microgrid under Uncertainty Based on Interval Optimization
}

\author{
Guoping Zhang $\left(\mathbb{D},{ }^{1}\right.$ Weijun Wang $\mathbb{D},^{2}$ Jie Du $\mathbb{D}^{3},{ }^{3}$ and Haoyun Sheng $\mathbb{D}^{1}$ \\ ${ }^{1}$ Department of Military Installations, Army Logistics University of PLA, Chongqing 401331, China \\ ${ }^{2}$ Academy of Military Sciences, Institute of System Engineering, Beijing 100091, China \\ ${ }^{3}$ Electric Power Research Institute, Chongqing Electric Power Company, Chongqing 401123, China
}

Correspondence should be addressed to Weijun Wang; wjwang636@126.com

Received 7 August 2021; Revised 1 September 2021; Accepted 14 September 2021; Published 11 October 2021

Academic Editor: Yang Li

Copyright ( $\odot 2021$ Guoping Zhang et al. This is an open access article distributed under the Creative Commons Attribution License, which permits unrestricted use, distribution, and reproduction in any medium, provided the original work is properly cited.

\begin{abstract}
In order to analyse the impact of renewable generation and load uncertainties on the economic operation optimization of the island microgrid, a multiobjective economic optimal dispatch model under uncertainty based on interval optimization is proposed in this paper. The mathematical model of distributed generation and the prediction model of wind speed and wave generation are established. The uncertainties of renewable generation and load are described by the interval mathematical method. On this basis, the interval multiobjective optimal dispatch model is presented. For the "battery disgusting" users on the island, the battery cost is regarded as a separate optimization objective, and a multiobjective optimization objective function to minimize the economic cost, battery cost, and pollution emission of the island microgrid is discussed. An island microgrid, composed of wind turbine, photovoltaic, wave energy generation, diesel generator, and energy storage system, is chosen as a case study. The NSGA-II algorithm is applied to solve the multiobjective optimal problem. The results for deterministic forecast data and load are analysed, and the optimal operation scheme is obtained by the improved multiobjective grey target decision-making method. The influence of renewable generation fluctuations $\pm 10 \%, \pm 20 \%$, and $\pm 30 \%$ and the load fluctuations $\pm 10 \%$ and $\pm 20 \%$ on island microgrid operation optimization is discussed in detail, respectively. The relevant research results can provide a reference for formulating the operating scheme of the island microgrid.
\end{abstract}

\section{Introduction}

China is a large coastal country with many islands [1]. Due to distance from mainland, these islands cannot obtain power supply from mainland power system. For a long time, the power supply of islands has completely relied on traditional fossil fuel generators [2]. With the rise of fuel prices, the gradual depletion of fossil fuels, and human's increasing attention to environmental protection, the utilization of renewable resources to satisfy the energy demand of island locally is becoming more and more popular [3]. As an effective form of renewable energy utilization, microgrid plays a more and more important role in solving the electricity deficit problem on islands.

Due to the intermittent and random features of renewable resources such as wind and solar, efficient design and operation of isolated microgrid are becoming more important and influential as the penetration of renewable energy increases in microgrid [4]. Scholars at home and abroad have carried out a lot of research on the sizing and operation optimization of isolated microgrid on island. Ghaffari and Askarzadeh [5] chose the equal annual present cost of microgrid as the economic index, the renewable energy penetration as the environmental protection index, and the power supply economy and environmental protection as the optimization objectives and established a multiobjective optimal configuration model of island microgrid including wind, photovoltaic, diesel generator, and energy storage system, so as to provide the necessary basis for the optimal design of island microgrid. Chen et al. [6] proposed a microgrid economic optimization model considering equipment loss cost, operation and 
maintenance cost, fuel cost, and environmental protection conversion cost, the nondominated sorting genetic algorithm-II (NSGA-II) was used to obtain the optimal operation scheme, but the pollutant emission was not considered. In order to realize the joint optimization of electricity and desalted water on island, Liu et al. [7] discussed the impact of seawater desalination equipment on island microgrid and established a day-ahead operation optimization model including cost of freshwater, but only the operation cost was considered. Li et al. [8] developed a multiobjective dynamic optimal dispatching model for isolated microgrid to coordinate multiple different optimization objectives, including economic cost, environmental factors, and users experience, using $\theta$-dominance-based evolutionary algorithm. However, in all the above researches, the wave energy generation is not considered. Zhao et al. [9] presented a wind and wave prediction model and proposed a microenergy network optimization method of multienergy complementary model. To minimize power and heat load deviation of microenergy network and maximize user's satisfaction, the particle swarm optimization algorithm was used to address this problem. However, the impact of cost and pollutant emission on microgrid optimal dispatch is not considered.

Nevertheless, the deterministic forecast data has been used in the above research, which is inappropriate for isolated microgrid on island since the small-scale demand is hard to predict and the renewable energy generations are highly changeable [10]. At present, for the optimal operation of microgrid, the following methods are mostly deployed to deal with the uncertain factors, namely, prediction error [11], point estimation [12], fuzzy optimization [13, 14], stochastic optimization [15], scenario-based stochastic optimization [16], robust optimization [17], chance-constrained programming [18], interval optimization $[19,20]$, and so on. In order to deal with the uncertainties in microgrid operation optimization, Ahn and Moon [11] describe the uncertainties of photovoltaic and wind generation output by a certain percentage of the predicted values, but the percentage parameters are arbitrary, and the same values are taken in different dispatching periods, which is limited. Li et al. [12] deploy the point estimation to settle with the uncertainty caused by wind and discuss the impact of uncertain factors on multiobjective dispatching of microgrid. The point estimation method directly replaces the whole indicators with sampling indicators, which could inevitably have errors. In [13], the uncertainty of renewable resource is expressed as a fuzzy variable, the fuzzy membership degree is set, and the fuzzy dispatching model is established. However, the specific values of these membership degrees are subjectively determined by the power system dispatcher. In this way, the obtained optimal solution may be highly subjective. Zakariazadeh et al. [15] take the uncertainty of renewable energy as a random variable and consider the wind speed obeys Weibull distribution and the solar irradiation obeys Beta distribution. Then Monte Carlo method is applied to generate a large number of random numbers. However, whether it is proper to apply such standard probability density functions in microgrid optimal dispatch remains to be examined. Talari et al. [16] propose a scenario-based stochastic optimization approach, to consider the uncertainties of PV, wind generation, and load demand, a large number of scenes and their corresponding occurrence probabilities are generated by Monte Carlo simulation, and finally, the mixed-integer linear programming method is used to address the stochastic optimization model. However, with an increase in the number of the produced scenes, the calculation burden will rise exponentially, so it is usually computationally expensive. Liu et al. [17] present a robust multiobjective optimization method, and a min-max multiobjective optimization model is established to find the uncertain worst implementation. It provides a mathematical framework for modelling uncertain values by uncertainty set and optimizing problems based on the worst scenario. However, the worst scenario determined by robust optimization is often too conservative, which increases the operation cost of microgrid. Li et al. [18] propose a new optimal dispatching model by using chanceconstrained programming for the isolated microgrids. In this model, not only are the uncertainties of load and renewable resources considered, but also the uncertainty modelling of spinning reserves of energy storage system is included by means of probability constraints. The model is transformed into a solvable mixed-integer linear programming formulation via the proposed discretized step transformation approach in GAMS. But the optimization objective function only considers the total operation cost. Interval mathematics is used to deal with the uncertainties in microgrid [19]. Wang et al. [20] discuss the grid-connected microgrid with interval numbers. Take the minimum total operation cost of microgrid in one day as the objective function and realize the optimal operation of a grid-connected microgrid. However, in this work, the objective function needs to be linearized.

Although many fundamental microgrid optimal scheduling problems are formulated and solved, some research gaps still exist in the area as follows: (1) In previous works, wave energy generation was usually not considered in the economic operation optimization of isolated microgrid on island, but with the fast development of ocean energy utilization technology in the past decades, wave energy generation has gradually become a feasible approach to provide electric energy for offshore isolated islands. Therefore, it is necessary to take the wave energy generation into account for island microgrid optimal dispatch. (2) At the same time, most of the existing studies on the economic operation optimization of island microgrid do not consider the uncertainty of renewable resources and load demand; that is, the predicted data is directly used as a determined value for operation optimization and results in a gap between the optimization results and the actual operation to a certain extent. (3) In researches where uncertainties of renewable resources or load demand are considered, the uncertainty modelling process is often complex and has many parameters, the probability distribution needs to be specified upfront, or the optimization results can only give the possible scenarios and their probability of occurrence. There is a lack of an easy-to-understand and simple modelling method considering uncertainty. 
To address the above concerns, this work proposes a multiobjective economic dispatch model based on interval optimization to deal with the optimal problem of island microgrid under uncertainties. The main contributions of this study are as follows:

(i) An optimal dispatch model for island isolated microgrid incorporating multiobjective operation optimization and interval uncertainties is proposed. In this model, the interval mathematical method is used to cope with the uncertainties of renewable generation and load demand. The modelling process is easy to implement and the model has fewer parameters.

(ii) For the "battery disgusting" users on islands, the battery cost is taken as a separate optimization objective, and the multiobjective optimization model to minimize the economic cost, battery cost, and pollutant emission is established in this paper. An improved multiobjective grey target decisionmaking method is applied to balance the tradeoff among multiple objectives.

(iii) The wave energy generation is taken into account for the island isolated microgrid system. At the same time, a prediction model between wind speed and wave energy generation output power is presented.

(iv) The optimization results directly present the distribution interval of multiple objectives, which is convenient for microgrid system operators to evaluate the impact caused by uncertainties. This approach is computational efficiency, which will be shown in the case study section.

The structure of this paper is as follows. The introduction is given in Section 1. In Section 2, the mathematical model of distributed generation is established. Section 3 presents the multiobjective optimization modelling. Section 4 explains the proposed methodology. The results are discussed in Section 5. The conclusion is given in Section 6.

\section{Modelling of an Island Microgrid}

2.1. Microgrid Structure. The structure of an island microgrid is shown in Figure 1. The system is composed of photovoltaic system (PV), wind turbines (WT), wave energy generation (WEG), diesel generator (DG), energy storage system (ESS), power conversion system (PCS), energy management system (EMS), and load demand.

\subsection{Component Modelling}

2.2.1. PV System. The output power of the PV system is not only related to its own technical parameters but also related to solar irradiation and temperature. Its output power can be expressed as [21]

$$
P_{\mathrm{PV}}(t)=P_{\mathrm{PV}-\text { rate }} \cdot \frac{I_{\mathrm{PV}}(t)}{I_{\mathrm{STC}}} \cdot\left[1-\alpha_{\mathrm{TP}}\left(T_{\mathrm{PV}}(t)-T_{\mathrm{STC}}\right)\right],
$$

where $P_{\mathrm{PV}}(t)$ is the real output power of PV system, $\mathrm{kW}$, $P_{\mathrm{PV} \_ \text {rate }}$ is the rated capacity of $\mathrm{PV}$ array, $I_{\mathrm{PV}}(t)$ is the actual solar irradiation on the PV panel, $\alpha_{\mathrm{TP}}$ is the temperature factor of PV panel $\left(\% /{ }^{\circ} \mathrm{C}\right), I_{\mathrm{STC}}$ and $T_{\mathrm{STC}}$ are the solar irradiation and temperature under standard test condition, respectively, and $T_{\mathrm{PV}}(t)$ is the temperature on the surface of PV panel; it is related to solar irradiation and ambient temperature [22]:

$$
T_{\mathrm{PV}}(t)=T_{\mathrm{amd}}+\varepsilon_{\mathrm{PV}} \cdot \frac{I_{\mathrm{PV}}(t)}{1000},
$$

where $T_{\mathrm{amd}}$ is the ambient temperature and $\varepsilon_{\mathrm{PV}}$ is the proportional coefficient related to the PV panel itself, with a value of 30 .

2.2.2. Wind Turbine. The relationship between the output power of wind turbine and wind speed can be formulated by a piecewise function [23]:

$$
P_{\mathrm{WT}}(t)= \begin{cases}0, & v(t)<v_{\mathrm{ci}}, v(t)>v_{\mathrm{co}}, \\ k_{1} v+k_{2}, & v_{\mathrm{ci}} \leq v(t)<v_{r} \quad k_{1}=\frac{P_{\mathrm{WT} \_ \text {rate }}}{v_{r}-v_{\mathrm{ci}}}, k_{2}=-k_{1} v_{\mathrm{ci}}, \\ P_{\text {WT_rate }}, & v_{r} \leq v(t) \leq v_{\mathrm{co}},\end{cases}
$$

where $P_{\mathrm{WT} \_ \text {rate }}$ is the rated power of wind turbine, $v(t)$ is the actual wind speed, $\mathrm{m} / \mathrm{s}, v_{r}$ is the rated wind speed of wind turbine, and $v_{\mathrm{ci}}$ and $v_{\mathrm{co}}$ refer to the cut-in and cut-out wind speed of WT, respectively.

2.2.3. Wave Energy Generation. Wave energy has large reserves and high energy density and has strong seasonal characteristics. In China's sea areas, the power generated by wave energy is usually large in autumn and winter, especially near islands [24]. Wave is essentially driven by wind. At present, wind speed prediction has been widely studied and applied in power system. Based on the wave generation mechanism, it is feasible to use wind and wave correlation to predict wave data.

In the field of marine research, the wave power density is generally evaluated by the wave power on the wavefront width, it is formulated as 


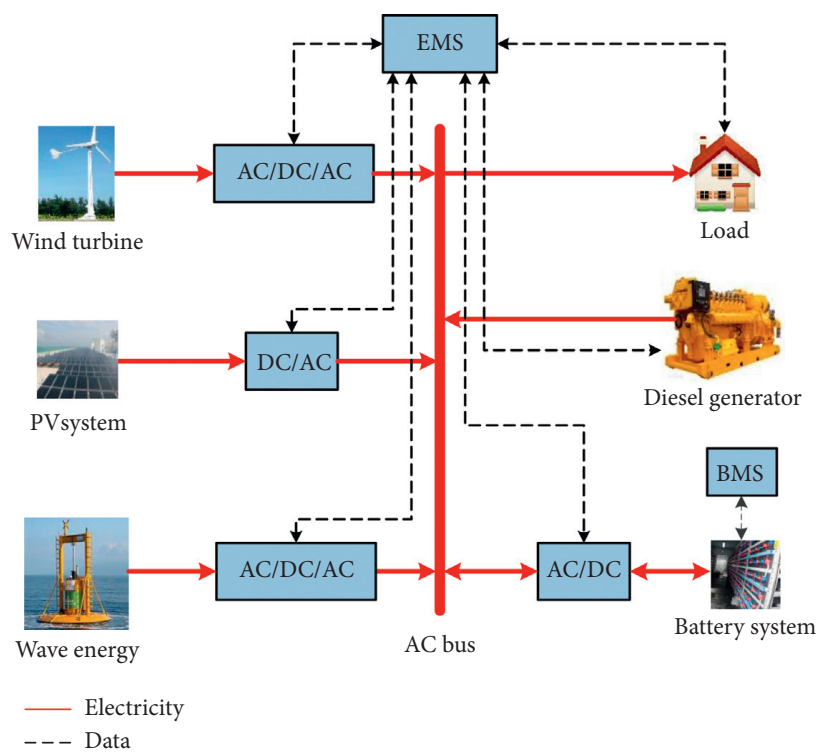

Figure 1: The structure of the island microgrid.

$$
P_{W}=\frac{\rho g^{2}}{64 \pi} h_{W}^{2} T_{W},
$$

where $\rho$ is the density of seawater, $\mathrm{kg} / \mathrm{m}^{3}, g$ is the gravitational acceleration, $9.8 \mathrm{~m} / \mathrm{s}^{2}$, and $h_{W}$ and $T_{W}$ are the height and period of the wave, respectively.

Wave is closely related to wind speed. The parameters can be obtained indirectly through wind data. The prediction model of wind speed and wave is [25]

$$
\left\{\begin{array}{l}
h_{W}=a v^{b}, \\
T_{W}=c v^{d},
\end{array}\right.
$$

where $v$ is the wind speed, $\mathrm{m} / \mathrm{s}, a, b, c$, and $d$ are the model parameters, which can be obtained by fitting the measured data, and the values are $0.03,1.62,5.15$, and 0.46 , respectively [26].

2.2.4. Diesel Generator. The fuel consumed by diesel generator is related to its structure and characteristics, and the expression of fuel cost is [27]

$$
F_{\mathrm{DG}}(t)=a+b \cdot P_{\mathrm{DG}}(t)+c \cdot P_{\mathrm{DG}}^{2}(t)
$$

where $a, b$, and $c$ are cost parameters of diesel generator, which are $6,0.012$, and $8.4 \times 10^{-4}$, respectively.

2.2.5. Energy Storage System. The state of charge (SOC) and output power of energy storage system satisfy the following relationship [28]:

$$
\operatorname{SOC}(t)= \begin{cases}(1-\delta) \cdot \operatorname{SOC}(t-1)+\frac{1}{\eta_{\text {cha }}} \cdot P_{\mathrm{ESS}}(t), & P_{\mathrm{ESS}}(t) \leq 0, \\ (1-\delta) \cdot \operatorname{SOC}(t-1)+\eta_{\text {discha }} \cdot P_{\mathrm{ESS}}(t), & P_{\mathrm{ESS}}(t)>0,\end{cases}
$$

where $\operatorname{SOC}(t)$ is the SOC of energy storage system at time $t$, $\%, \delta$ is the self-discharging rate, $P_{\mathrm{ESS}}(t)$ is the output power at time $t$, positive indicates discharging and negative indicates charging, and $\eta_{\text {cha }}$ and $\eta_{\text {discha }}$ are the charging and discharging efficiency, respectively.

\section{Objective Function}

3.1. Multiobjective Model. For the "battery disgusting" users on island, this paper takes the battery cost as a separate optimization objective and establishes a multiobjective function with minimizing the economic cost, battery cost, and pollutant emission simultaneously for island microgrid:

$$
\begin{array}{cl}
\min & {\left[f_{1}(\mathbf{x}, \mathbf{u}), f_{2}(\mathbf{x}, \mathbf{u}), \ldots, f_{M}(\mathbf{x}, \mathbf{u})\right]} \\
\text { s.t. } & g(\mathbf{x}, \mathbf{u})=0 \\
& h(\mathbf{x}, \mathbf{u}) \leq 0 \\
& \mathbf{u} \in\left[\mathbf{u}^{-}, \mathbf{u}^{+}\right]
\end{array}
$$

where $f_{i}(\mathbf{x}, \mathbf{u})$ is the optimization subobjective, $\mathbf{x}$ is the decision variable, $g(\mathbf{x}, \mathbf{u})$ represents the equality constraints, $h(\mathbf{x}, \mathbf{u})$ 
expresses the inequality constraints, and $\mathbf{u}^{-}$and $\mathbf{u}^{+}$are the lower and upper limits of uncertain variables; namely,

$$
\begin{aligned}
P_{\mathrm{PV}}(t) & \in\left[P_{\mathrm{PV}}^{-}(t), P_{\mathrm{PV}}^{+}(t)\right], \\
P_{\mathrm{WT}}(t) & \in\left[P_{\mathrm{WT}}^{-}(t), P_{\mathrm{WT}}^{+}(t)\right], \\
P_{\mathrm{WEG}}(t) & \in\left[P_{\mathrm{WEG}}^{-}(t), P_{\mathrm{WEG}}^{+}(t)\right], \\
P_{\mathrm{Load}}(t) & \in\left[P_{\text {Load }}^{-}(t), P_{\text {Load }}^{+}(t)\right],
\end{aligned}
$$

where $P_{\mathrm{PV}}(t), P_{\mathrm{WT}}(t), P_{\mathrm{WEG}}(t)$, and $P_{\mathrm{Load}}(t)$ represent the output power of PV system, wind turbine, wave energy generation, and load at time $t$, respectively.

3.1.1. Economic Cost. Economic cost mainly considers equipment depreciation cost, fuel cost, and operation and maintenance (O\&M) cost.

\section{(1) Depreciation Cost}

$$
C_{\mathrm{DP}}=\sum_{i=1}^{m} \sum_{t=1}^{T} \frac{C_{\mathrm{ACC}, i}}{8760 k_{i}} \cdot \frac{r(1+r)^{n_{i}}}{(1+r)^{n_{i}}-1} \cdot P_{i}(t),
$$

where $C_{\mathrm{ACC}, i}$ is the installation cost per unit capacity of the $i$ th distributed generation, $\$ / \mathrm{kW}, r$ is the annual interest rate, $\%, n_{i}$ is the service lifetime of the $i$ th distributed generation, $k_{i}$ represents the capacity factor of the $i$ th distributed generation, and its calculation formula is

$$
k_{i}=\frac{\sum_{t=1}^{8760} P_{i}(t)}{\sum_{t=1}^{8760} P_{r, i}}
$$

where $P_{r i}$ and $P_{i}(t)$ represent the rated power of the $i$ th distributed generation and the power at the $t$ th period, $\mathrm{kW}$.

(2) Fuel Cost. Since photovoltaic and wind power generation use renewable resources, the fuel costs of both are not considered. The fuel cost of diesel generator can be expressed as

$$
C_{F}=\sum_{t=1}^{T} F_{\mathrm{DG}}(t)
$$

where $F_{\mathrm{DG}}(t)$ is the fuel cost of diesel generator at time $t$.

(3) O\&M Cost. The O\&M cost of distributed generation unit is linearly related to the electric energy generated. The expression is

$$
C_{\mathrm{OM}}=\sum_{t=1}^{T} \sum_{i=1}^{m} K_{\mathrm{OM}, i} \cdot P_{i}(t)
$$

where $P_{i}(t)$ represents the output power of $\mathrm{PV}$, wind turbine, wave energy generation, and diesel generator and $k_{\mathrm{OM}, i}$ is the operation and maintenance cost coefficient of each distributed generation, $\$ / \mathrm{kWh}$.

3.1.2. Battery Cost. During the operation of energy storage batteries, depreciation costs and O\&M expenses occur at the same time.

(1) Battery Depreciation Cost. The depreciation cost of battery is calculated by using the replacement cost and the times of charging and discharging within the battery's lifetime [29].

$$
C_{\text {ESS,loss }}=n_{B} \cdot \frac{C_{\mathrm{ESS}, \mathrm{rep}}}{n_{\mathrm{BN}}},
$$

where $C_{\mathrm{ESS} \text {,rep }}$ is the battery replacement cost, $n_{B}$ refers to the charging and discharging times of energy storage battery in a dispatching period, $n_{\mathrm{BN}}$ is the rated charging and discharging times of battery in its life cycle, and its relationship with depth of discharging (DOD) of the battery can be expressed as [30]

$$
n_{\mathrm{BN}}=a_{1}+a_{2} \cdot e^{-a_{3} \cdot \mathrm{DOD}}+a_{4} e^{-a_{5} \cdot \mathrm{DOD}}
$$

where DOD is the depth of discharging of battery, $\mathrm{DOD}=1-\mathrm{SOC}$, and $a_{1}$ to $a_{5}$ are constants, which can be obtained by fitting the experimental data.

(2) O\&M Cost of Battery

$$
C_{\mathrm{ESS}, \mathrm{OM}}=\sum_{t=1}^{T} C_{\mathrm{OM}, \mathrm{ESS}}(t)=\sum_{t=1}^{T} K_{\mathrm{OM}, \mathrm{ESS}} \cdot\left|P_{\mathrm{ESS}}(t)\right|,
$$

where $P_{\mathrm{ESS}}(t)$ is the charging and discharging power of battery in the $t$ th period, which is positive during discharging and negative during charging, and $K_{\mathrm{OM} \text {,ESS }}(t)$ is the unit operation and maintenance cost coefficient of battery, $\$ / \mathrm{kWh}$.

(3) Pollutant Emission. Traditional fossil fuel generators will not only release a large amount of greenhouse gas $\mathrm{CO}_{2}$ but also emit toxic and harmful gases such as $\mathrm{SO}_{2}$ and $\mathrm{NO}_{X}$, which is harmful to the ecological environment and human survival. Therefore, the environmental protection department will levy corresponding environmental damage compensation for the environmental treatment of pollutant emission, that is, environmental protection cost [31]:

$$
E_{m}=\sum_{i=1}^{m} \sum_{j=1}^{n} \sum_{t=1}^{T} Q_{i j} \cdot P_{i}(t)
$$

where $Q_{i j}$ is the emission of the $j$-th pollutants of the $i$ th distributed generation, $\mathrm{g} / \mathrm{kWh}, m$ is the number of distributed generations, and $n$ is the number of types of pollutants. Due to the different degree of toxicity caused by different pollutant emissions, in order to facilitate comparison, the emissions of $\mathrm{SO}_{2}$ and $\mathrm{NO}_{X}$ are uniformly transformed into $\mathrm{CO}_{2}$ emissions according to the environmental protection punishment imposed by the environmental protection department for unit harmful emissions.

3.2. Constraint Condition. Considering the power balance of microgrid system and the physical limitations of distributed generation units, the above multiobjective optimization model must also meet the following constraints.

3.2.1. Power Balance Constraint. In order to ensure a reliable power supply, in any case, the total output power of various power generation units and load consumption in one system 
must always be balanced. Considering that the equality constraint described by the predicted data of load and renewable energy generation are actually difficult to satisfy, the interval mathematical method is used to describe the power balance constraint [32]:

$$
\left[P_{\mathrm{Load}}(t)\right]-\left[P_{\mathrm{DG}}(t)\right]-\left[P_{\mathrm{ESS}}(t)\right]=\left[P_{\sum}^{-}(t), P_{\sum}^{+}(t)\right],
$$

where $P_{\sum}^{-}(t)$ and $P_{\sum}^{+}(t)$ represent the upper and lower limits of the fluctuation range of the linear combination of $\mathrm{PV}$, wind turbine, and wave energy generation, respectively.

For the equality constraint that uses interval numbers to describe uncertainties, they can be transformed into deterministic equality constraint:

$$
\left\{\begin{array}{l}
P_{\mathrm{Load}}^{-}(t)-P_{\mathrm{DG}}^{-}(t)-P_{\mathrm{ESS}}^{-}(t)=P_{\mathrm{PV}}^{-}(t)+P_{\mathrm{WT}}^{-}(t)+P_{\mathrm{WEG}}^{-}(t), \\
P_{\mathrm{Load}}^{+}(t)-P_{\mathrm{DG}}^{+}(t)-P_{\mathrm{ESS}}^{+}(t)=P_{\mathrm{PV}}^{+}(t)+P_{\mathrm{WT}}^{+}(t)+P_{\mathrm{WEG}}^{+}(t) .
\end{array}\right.
$$

3.2.2. Generation Capacity Constraint. Due to the physical limitation of distributed generation unit, in order to maintain the operation stability and safety, its actual output power will be strictly limited between the upper and lower limits.

$$
P_{i, \text { min }} \leq P_{i}(t) \leq P_{i, \max },
$$

where $P_{i}(t)$ is the output power of DG, PV, WT, and WEG and $P_{i, \min }$ and $P_{i, \max }$ represent the upper and lower limits of power generation units. For PV, WT, and WEG, the minimum output power is zero and the maximum output power is its installed capacity. For diesel generator, considering operation economy and spinning reserves, its maximum and minimum power can be set according to the manufacturer's recommendations. For the energy storage system, the output power is positive and its range is $\left(0, P_{\max }\right)$ when the battery is discharging; the output power is negative and its range is $\left(-P_{\max }, 0\right)$ when the battery is charging.

3.2.3. Climbing Rate Constraint. The operation of diesel generator is also limited by the climbing rate.

$$
r_{\mathrm{DG}}^{\text {down }} \Delta t \leq P_{\mathrm{DG}}(t)-P_{\mathrm{DG}}(t-1) \leq r_{\mathrm{DG}}^{\mathrm{up}} \Delta t,
$$

where $r_{\mathrm{DG}}^{\mathrm{down}}$ and $r_{\mathrm{DG}}^{\mathrm{up}}$ represent the downward and upward climbing rates of diesel generator, respectively.

3.2.4. Battery SOC Constraint. In order to protect the energy storage system from being damaged and prolong its service lifetime, the battery will avoid overcharging or overdischarging, and its state of charge should be limited within a reasonable range. At the beginning and end of a dispatching period, the state of charge would be consistent.

$$
\begin{aligned}
\mathrm{SOC}_{\text {min }} & \leq \mathrm{SOC}(t) \leq \mathrm{SOC}_{\text {max }}, \\
\mathrm{SOC}_{0} & =\mathrm{SOC}_{T} .
\end{aligned}
$$

\section{Methodology}

In 2002, to overcome the disadvantages of traditional nondominated sorting genetic algorithm (NSGA), such as high computational complexity, lack of elites, and the need to specify sharing parameters, Deb et al. proposed a fast nondominated sorting genetic algorithm with elite strategy, namely, the NSGA-II algorithm [33].

4.1. Overview of NSGA-II. The basic idea of NSGA-II is as follows. Firstly, the initial population with size $N$ is randomly generated, the value of each objective function is calculated, the nondominated ranking is carried out, and the individual crowding distance is calculated. Secondly, the first generation offspring population is produced through three basic operations, namely, selection, crossover, and mutation, respectively. Thirdly, the parent population and child population are merged by fast nondominated sorting method. At the same time, the crowding distance of individuals in each nondominated layer is calculated. According to the nondominated relationship and the crowding distance of individuals, appropriate individuals are chosen to form a new parent population. Finally, a new population is generated by preserving elite strategy operation. The flowchart of NSGA-II is shown in Figure 2.

4.2. Constraint Dominating Mechanism. The general form of multiobjective optimization objective function can be expressed as the following formula:

$$
\begin{cases}\min & F=\left\{f_{1}(x), f_{2}(x), \ldots, f_{m}(x)\right\} \\ & g_{j}(x) \leq 0, j=1,2, \ldots, p \\ \text { s.t. } & h_{j}(x)=0, j=p+1, \ldots, q\end{cases}
$$

where $x$ is the decision variable, $f_{i}(x)$ represents the $i$ th optimization subobjective, and $g_{j}(x)$ and $h_{j}(x)$ represent the inequality and equality constraints, respectively.

There are many equality and inequality constraints in the microgrid optimization model. How to treat these constraints directly affects the final optimization results. These constraints can be divided into two categories: unit level constraints and system level constraints. The unit level constraints are mainly restricted by the physical limitations of distributed generation unit, which can be easily addressed by restricting its output power between the upper and lower limits. System level constraints mainly include system power balance constraints (equation (18)) and energy storage system constraints (equations (22) and (23)), which are directly related to the spatiotemporal state of decision variables and are often difficult to deal with.

In order to facilitate calculation, the equality constraints are transformed into inequality constraints in this paper. Therefore, the constraint violation (CV) of individual $x$ on the $j$-th constraint can be expressed as 


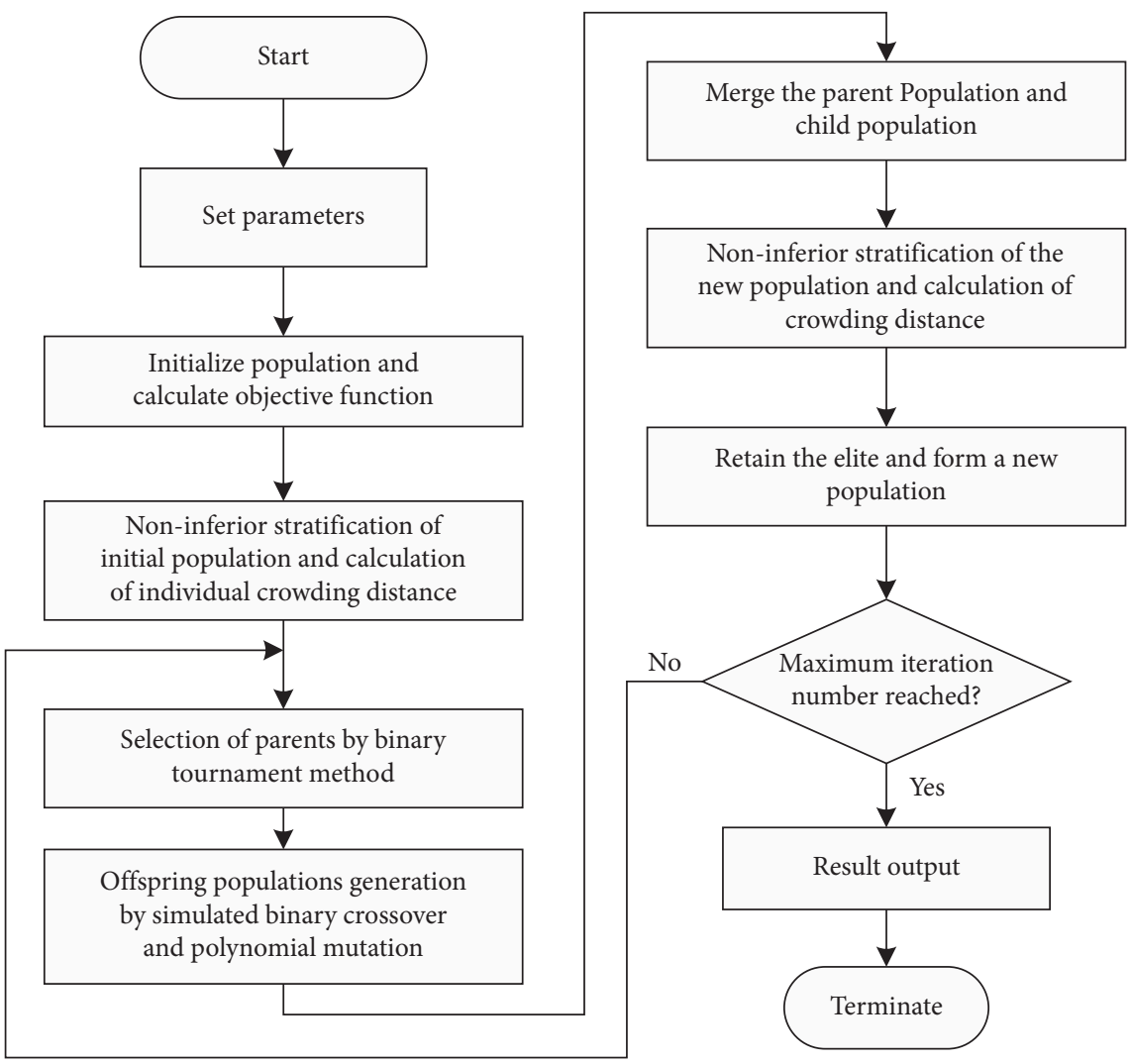

Figure 2: The flowchart of NSGA-II.

$$
G_{j}(x)= \begin{cases}\max \left\{g_{j}(x), 0\right\}, & 1 \leq j \leq p, \\ \max \left\{\left|h_{j}(x)\right|-\delta, 0\right\}, & p+1 \leq j \leq q,\end{cases}
$$

where $\delta$ is the tolerance parameter of equality constraint, usually a small positive number. Therefore, the total constraint violation of individual $x$ is

$$
\mathrm{CV}=\sum_{j=p+1}^{q} G_{j}(x) \text {. }
$$

This paper adopts the constrained domination principle (CDP) [34], as follows:

(1) Feasible solutions take priority over infeasible solutions

(2) If both are feasible solutions, the nondominated solution takes priority

(3) If both are infeasible solutions, the solution with small constraint violation takes priority

4.3. Multiobjective Decision-Making. In order to improve the authenticity and feasibility of multiobjective decisionmaking and avoid the preference of artificial weight or expert judgment, the multiobjective grey target decision-making method based on entropy is adopted to select the optimal scheme from the Pareto optimal front solution set in this paper. Considering the influence of correlation, different dimensions, and important differences among indicators on decision-making effect, the weighted Markov distance is used to improve the traditional grey target decision-making method [35].

Step 1. Initialize the $m$-dimensional multiobjective decision matrix.

$$
\mathbf{X}=\left(x_{i j}\right)_{m \times n}=\left[\begin{array}{ccc}
x_{11} & \cdots & x_{1 n} \\
\vdots & \ddots & \vdots \\
x_{m 1} & \cdots & x_{m n}
\end{array}\right]
$$

Step 2. Calculate the weight coefficient of each objective by entropy weight method.

$$
\begin{aligned}
y_{i j} & =\frac{x_{i j}}{\sum_{i=1}^{m} x_{i j}}, \quad x_{i j} \geq 0, \\
E_{j} & =-\frac{1}{\ln m} \sum_{i=1}^{m} x_{i j} \ln y_{i j}, \quad E_{j}>0, \\
\omega_{j} & =\frac{\left(1-E_{j}\right)}{\sum_{j=1}^{n}\left(1-E_{j}\right)}, \\
\sum_{j=1}^{m} \omega_{j} & =1 .
\end{aligned}
$$

Step 3. Normalize the decision matrix. 


$$
\begin{aligned}
& z_{j}=\frac{1}{m} \sum_{i=1}^{m} x_{i j}, \quad j=1,2, \ldots, n, \\
& v_{i j}=\frac{x_{i j}-z_{j}}{\max \left\{\max _{1 \leq i \leq m}\left\{x_{i j}\right\}-z_{j}, z_{j}-\min _{1 \leq i \leq m}\left\{x_{i j}\right\}\right\}} .
\end{aligned}
$$

Step 4. Define the bull's-eye vector.

$$
\begin{aligned}
\mathbf{v}_{j}^{0} & =\min \left\{v_{i j} \mid 1 \leq i \leq m\right\}, \quad j=1,2, \ldots, n, \\
\mathbf{v}^{0} & =\left\{\mathbf{v}_{1}^{0}, \mathbf{v}_{2}^{0}, \ldots, \mathbf{v}_{n}^{0}\right\} .
\end{aligned}
$$

Step 5. Calculate the bull's-eye distance.

According to the grey target theory, the closer the objective of each solution is to the target centre, the better the solution is. The bull's-eye distance is

$$
d_{i}=\sqrt{\left(v_{i}-\mathbf{v}^{0}\right)^{T} \Omega \sigma^{-1} \Omega\left(v_{i}-\mathbf{v}^{0}\right)},
$$

where $\sigma$ is the sample covariance matrix, $\Omega$ is the weight matrix, and $\Omega=\operatorname{diag}\left(\sqrt{\omega_{1}}, \sqrt{\omega_{2}}, \ldots, \sqrt{\omega_{3}}\right)$.

\section{Results and Discussion}

5.1. Case Study. In order to verify the effectiveness and performance of the proposed multiobjective optimal dispatch model based on interval optimization, an island microgrid including PV/WT/WEG/DG/ESS is taken as an example. The optimization model takes into account the daily dispatch period with one hour as the time interval. In this study, the proposed optimal dispatch model and the solving algorithm are developed and simulated in MATLAB software R2020b. The workstation Dell Precision M3800 with Intel (R) Core ${ }^{\mathrm{TM}} \mathrm{i} 7-4712 \mathrm{HQ}$ is chosen as the computing platform.

The hourly forecast load demand is shown in Figure 3. The hourly predicted output power of PV, WT, and WEG in one day is depicted in Figure 4.

The operating parameters of different generation units are presented in Table 1. The specification of energy storage system is given in Table 2. The pollutant emission and corresponding penalty coefficient are shown in Table 3. The parameters of the NSGA-II algorithm are set as follows: the population size is 100 , the maximum number of iterations is 1000 , and the crossover rate and mutation rate are 1.0 and 0.1 , respectively.

5.2. Results' Analysis. In this paper, the NSGA-II algorithm is used to realize the interval optimization for the day-ahead economic optimal operation of island microgrid. On the basis of the predicted renewable generation and load curve, three objective Pareto front solutions set are calculated. Then the optimization results of four schemes are compared, namely, scheme 1 the lowest economic cost, scheme 2 the lowest battery cost, scheme 3 the lowest pollutant emission, and scheme 4 the optimal operation scheme obtained, by

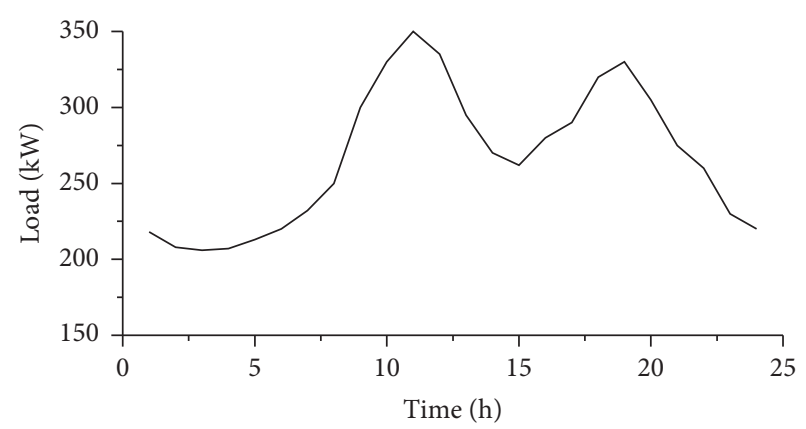

FIgURE 3: The hourly forecast load demand.

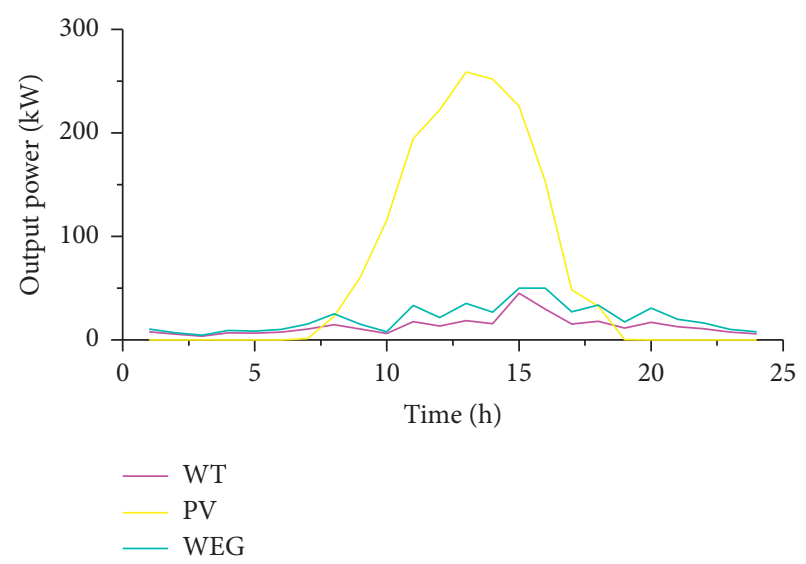

Figure 4: The hourly forecast output of renewable generations.

TABLE 1: Operating parameters of different generation units.

\begin{tabular}{lccccc}
\hline Type & $\begin{array}{c}P_{r, i} \\
(\mathrm{~kW})\end{array}$ & $\begin{array}{c}C_{\mathrm{ACC}, i} \\
(\$ / \mathrm{kW})\end{array}$ & $N_{i}$ (year) & $\begin{array}{c}K_{\mathrm{OM}, i} \\
(\$ / \mathrm{kWh})\end{array}$ & $k_{i}(\%)$ \\
\hline PV & 300 & 2.375 & 20 & 0.0096 & 29.34 \\
WT & 50 & 1.2 & 15 & 0.0296 & 22.13 \\
WEG & 50 & 1.2 & 15 & 0.0296 & 22.13 \\
DG & 400 & 1.306 & 10 & 0.0880 & 55.94 \\
ESS & 300 & 2.5 & 10 & 0.0648 & 32.47 \\
\hline
\end{tabular}

TABle 2: The specification of the energy storage system.

\begin{tabular}{lccccc}
\hline Type & $\mathrm{SOC}_{\min }$ & $\mathrm{SOC}_{\max }$ & $\eta$ & $\delta$ & $C_{\text {rep }}(\$ / \mathrm{kWh})$ \\
\hline Battery & 0.4 & 0.9 & 0.9 & 0.01 & 1000 \\
\hline
\end{tabular}

TABle 3: Pollutant emission coefficients of different generation units.

\begin{tabular}{lccccc}
\hline & & \multicolumn{4}{c}{$\begin{array}{c}\text { Pollutant emission } \\
\left(\mathrm{g} \cdot \mathrm{kW}^{-1} \cdot \mathrm{h}^{-1}\right)\end{array}$} \\
Type & Penalty coefficient $(\$ / \mathrm{kg})$ & $\mathrm{TV}$ & $\mathrm{WT}$ & WEG & DG \\
\hline $\mathrm{NO}_{x}$ & 10.49 & 0 & 0 & 0 & 9.89 \\
$\mathrm{CO}_{2}$ & 0.035 & 0 & 0 & 0 & 647 \\
$\mathrm{SO}_{2}$ & 2.47 & 0 & 0 & 0 & 0.206 \\
\hline
\end{tabular}

using the grey target decision-making method. Finally, the multiobjective interval optimization considering load and renewable generation uncertainties is discussed in detail. 
5.2.1. Deterministic Optimization. The three objective Pareto front solutions set is obtained by using the above approach, as shown in Figure 5. It can be seen that, for the island microgrid, the economic cost is linearly positively correlated with $\mathrm{CO}_{2}$ emission, and the battery cost is negatively correlated with economic cost. Therefore, for island microgrid, there is a multiobjective optimal decision-making problem between economic cost and battery cost. The multiobjective grey target decision-making method based on entropy weight is used to obtain the optimal operation scheme of microgrid from the multiobjective Pareto front solution set, as shown in Figure 5(a). Therefore, the optimization results corresponding to the four schemes are obtained, as shown in Table 4 . When the battery cost reaches the maximum, the economic cost and $\mathrm{CO}_{2}$ emission drop to the minimum at the same time, which are 2284.01\$ and $870.46 \mathrm{~kg}$, respectively. When the economic cost and $\mathrm{CO}_{2}$ emission are the largest, the battery cost is the lowest, which is $70.91 \$$. Each objective value corresponding to the optimal scheme is between the maximum and the minimum, which reflects the idea of tradeoff among multiple objectives.

The output power curve of each distributed generation unit corresponding to the optimal operation scheme is shown in Figure 6. It can be seen that solar resources are abundant during daytime, the battery will be charged for about 7 hours until 16:00 p.m., and the maximum SOC will reach 0.9 . After discharging during the peak load at night, the SOC drops to the daily minimum at $21: 00$, which is about 0.65 . The SOC at the beginning and the end in one scheduling period is basically equal, with a difference of $0.7 \%$, and the SOC value satisfies the constraints. Due to the positive correlation between wave energy and wind speed, the output power of wave energy generation is consistent with that of wind energy generation, which proves the effectiveness of the wind speed and wave prediction model. Because of the high generation cost of diesel generator, the output power of diesel generator operates at the minimum economic output power when the solar irradiation is strong in the daytime and the load valley in the early morning, and the output power fluctuation of diesel generator is small throughout the whole day. The smooth output of diesel generator is advantageous to ease the mechanical wear of diesel generator and reduce the operation expenses of the whole system. At the same time, the optimal economic operation of microgrid is achieved by using the electricity transferability of energy storage system.

5.2.2. Renewable Energy under Uncertainty. The maximum fluctuation of renewable energy is $\pm 20 \%$ in [23]. Considering that the meteorological conditions on island are more changeable than those on mainland, the maximum fluctuation is selected as $\pm 30 \%$ in this paper. Assuming that the load curve is determined, the fluctuations of wind speed and solar irradiation based on the forecast data are $\pm 10 \%, \pm 20 \%$, and $\pm 30 \%$, respectively. The influence of renewable generation uncertainty on the multiobjective operation optimization of microgrid is analysed. The multiobjective Pareto front is shown in Figure 7, and the interval values corresponding to each objective are shown in Table 5 .

The interval width of economic cost and battery cost corresponding to renewable energy output greater than the predicted values is larger than that of renewable energy output less than the forecast data, which is more favourable to optimal dispatching between diesel generator and energy storage system. When the output power of renewable energy is less than the predicted values, the maximum value of economic cost and $\mathrm{CO}_{2}$ emission rises with the increase of the fluctuation of renewable generation, but the battery cost decreases. The reason is that, with the increase of the volatility of renewable generation, the net power $\left(P_{\mathrm{NET}}^{-}(t)=\right.$ $\left.P_{\mathrm{PV}}^{-}(t)+P_{\mathrm{WT}}^{-}(t)+P_{\mathrm{WEG}}^{-}(t)-P_{\text {Load }}(t)\right)$ of the microgrid system decreases, and the diesel generator needs to generate more electricity to balance the power shortage of the whole system. Consequently, the economic cost and $\mathrm{CO}_{2}$ emission increase. Consider that the economic cost of diesel generator is greater than that of renewable generation. The system has no excess net power need to be stored by energy storage battery. Therefore, the battery cost reduces. At this time, it is necessary to meet the load demand as much as possible, and the space for system operation optimization is small.

When the output power of renewable generation is greater than the forecast data, the net power $\left(P_{\mathrm{NET}}^{+}(t)=\right.$ $\left.P_{\mathrm{PV}}^{+}(t)+P_{\mathrm{WT}}^{+}(t)+P_{\mathrm{WEG}}^{+}(t)-P_{\text {Load }}(t)\right)$ of the system rises with the increase of the fluctuation of renewable energy. The more the net power is the better the time-shifting capacity of the energy storage system can be used to realize the "peak shaving and valley filling" of the whole microgrid system. Therefore, the maximum cost and interval width of energy storage system increase significantly, while the economic cost and $\mathrm{CO}_{2}$ emission decrease.

At the same time, it can also be found that parts of the Pareto front of renewable energy fluctuation of $+10 \%$ and $+20 \%$ are completely overlapped. Due to the charging and discharging cost of battery is lower than that of diesel generator, the energy storage system absorbs more lowcost renewable generation and releases electric energy to the microgrid system during the peak load. While there is more excess of renewable energy, the energy storage system cannot fully absorb the surplus renewable generation completely. When the fluctuation of renewable energy reaches $+30 \%$, the wind and solar abandoning is more serious. Finally, the interval width of renewable energy fluctuation $-10 \%$ intersects with $+10 \%$ and $+20 \%$, which just reflects the impact of uncertainties on the multiobjective operation optimization of the microgrid system.

5.2.3. Load under Uncertainty. Due to the influence of weather, holidays, and living habits, there is often a deviation between the predicted load curves and the actual ones. Assuming that the renewable generation outputs power according to the forecast data, the fluctuation of load curve based on the predicted value is $\pm 10 \%$ and $\pm 20 \%$, respectively. The impact of load fluctuation on microgrid operation optimization is discussed, and the multiobjective 


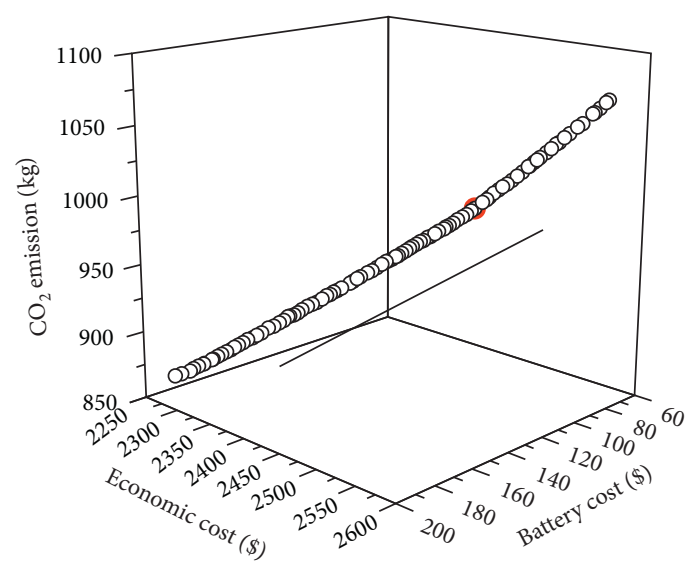

(a)

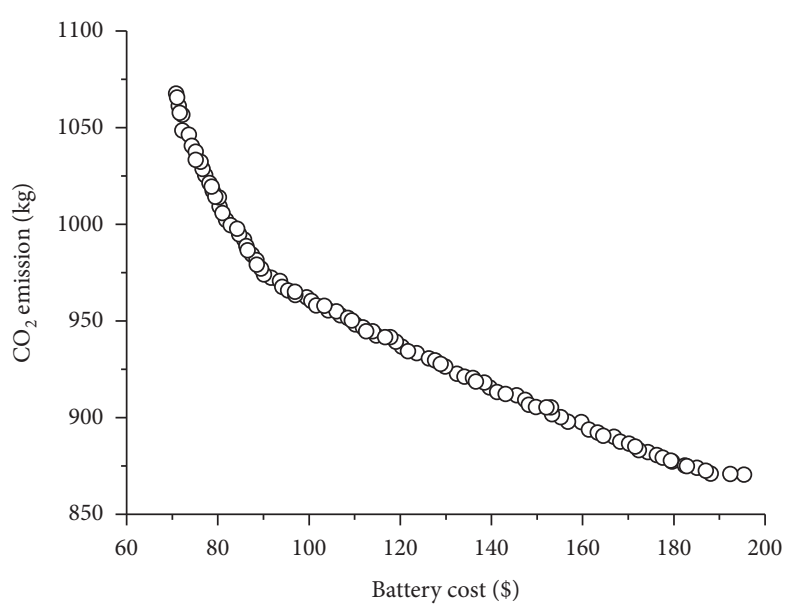

(c)

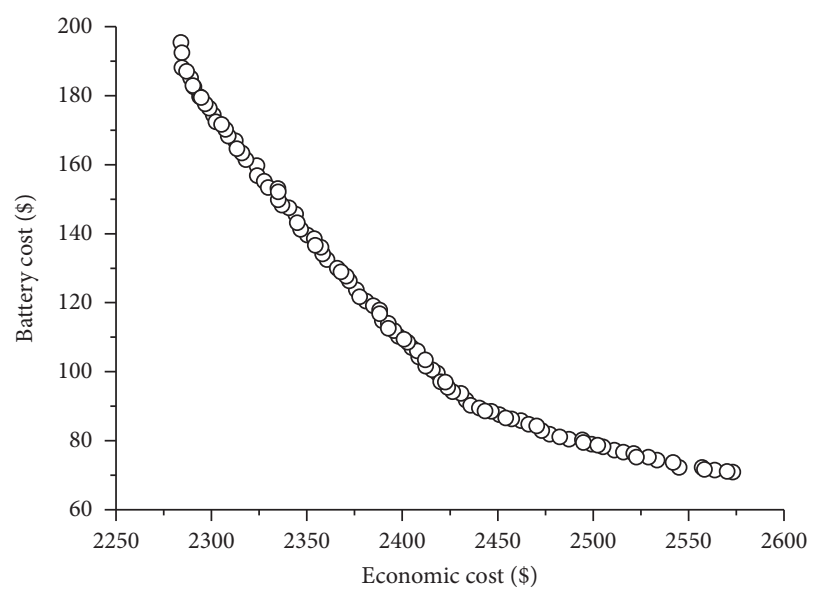

(b)

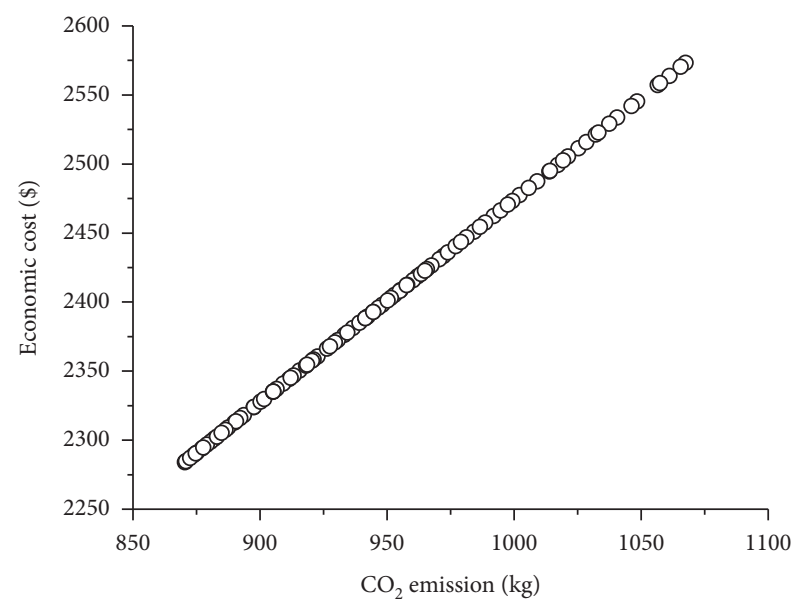

(d)

Figure 5: The multiobjective Pareto front solution set. (a) Triple-objective Pareto front. (b) Pareto front of economic cost and battery cost. (c) Pareto front of battery cost and $\mathrm{CO}_{2}$ emission. (d) Pareto front of $\mathrm{CO}_{2}$ emission and economic cost.

TABle 4: Costs and $\mathrm{CO}_{2}$ emission of different schemes.

\begin{tabular}{lccc}
\hline Scheme & Economic cost & Battery cost & $\mathrm{CO}_{2}$ emission \\
\hline The minimum of economic cost & 2284.01 & 195.39 & 870.46 \\
The minimum of battery cost & 2573.18 & 70.91 & 1067.57 \\
The minimum of $\mathrm{CO}_{2}$ emission & 2284.01 & 195.39 & 870.46 \\
The optimal scheme & 2443.44 & 88.59 & 979.14 \\
\hline
\end{tabular}

Pareto front is shown in Figure 8. The interval values corresponding to each objective are shown in Table 6. It can be seen that the larger the load fluctuation is, the smaller the interval width corresponding to economic cost, $\mathrm{CO}_{2}$ emission, and battery cost is, that is, the more stable each objective is. As the load increases from $-20 \%$ to $+20 \%$, the maximum value of economic cost and $\mathrm{CO}_{2}$ emission becomes larger and larger, and the maximum value of battery cost becomes smaller and smaller. This reflects the amplitude and direction of load fluctuation based on the predicted data will have an important influence on the optimal operation of microgrid.
5.2.4. Computational Efficiency Analysis. In order to evaluate the computational efficiency of the proposed method, the simulation for different scenarios runs 100 times, and the minimum, maximum, and average value of calculation time are obtained, as demonstrated in Table 7. In each simulation, the NSGA-II algorithm has a population size of 100, and the simulation iterates 1000 times at each run.

From Table 7, the average calculation time of deterministic optimization is just 11.77 seconds. Due to the consideration of uncertainties, the computation cost increases significantly but still does not exceed 30 seconds. 


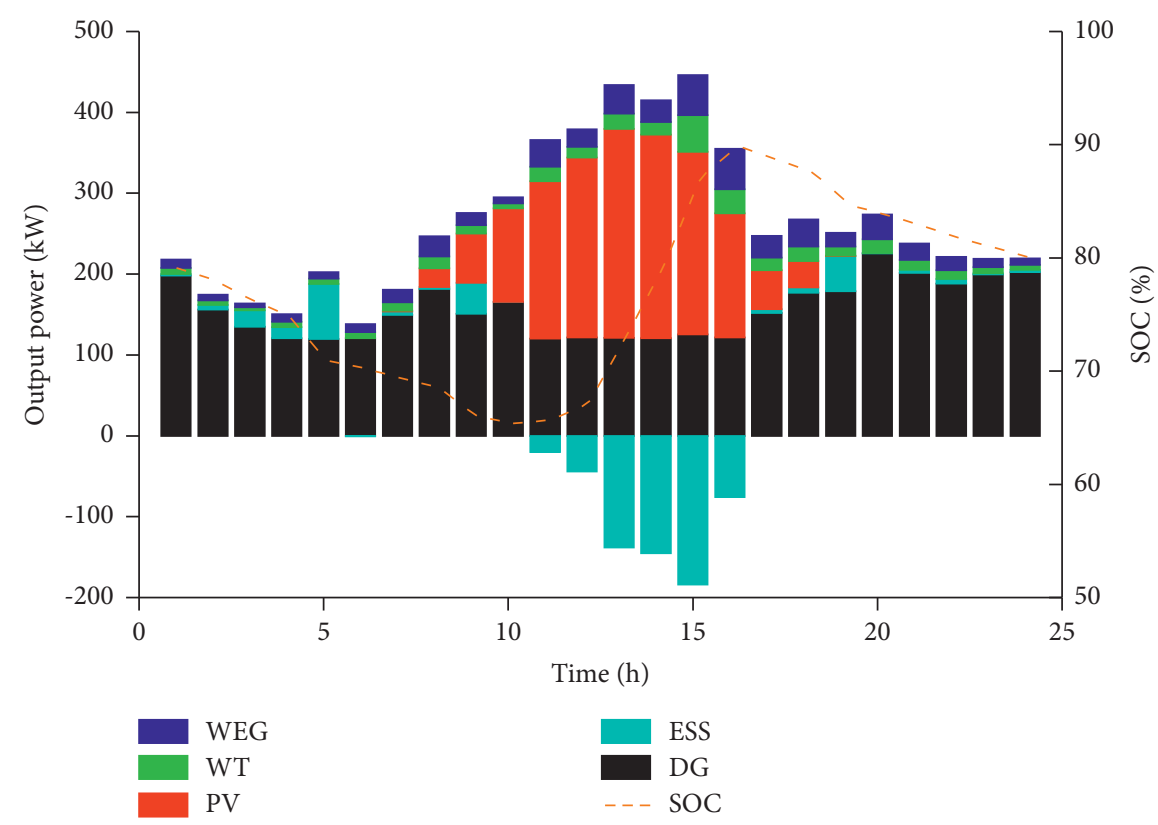

FIGURE 6: Output power of generation units for the optimal scheme.

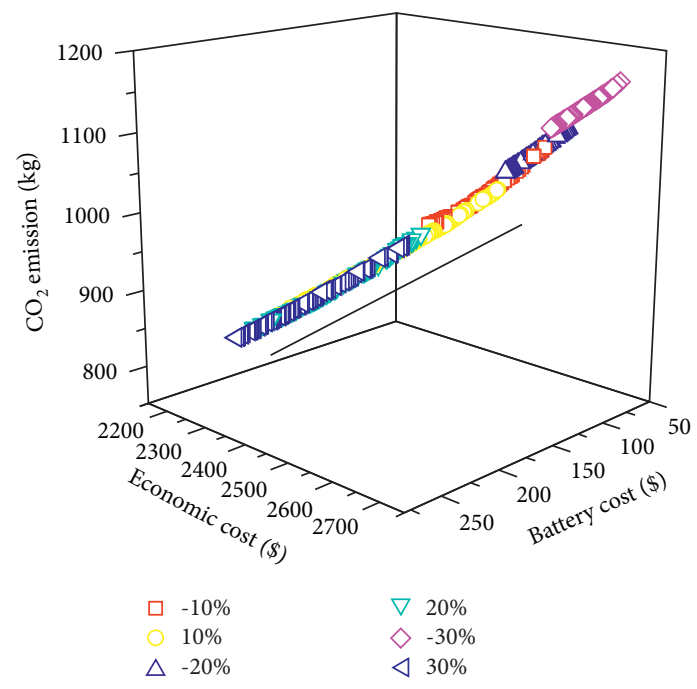

(a)

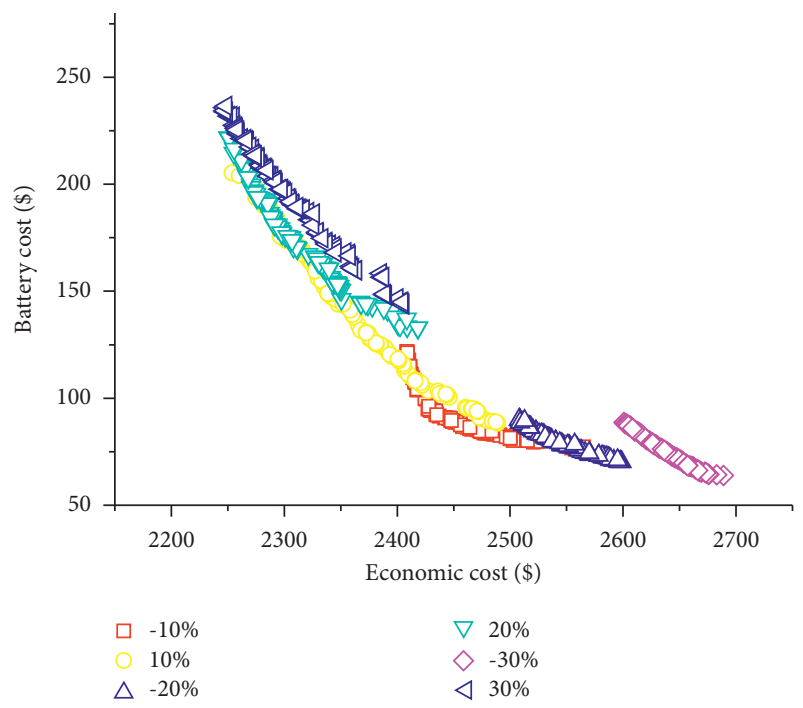

(b)

Figure 7: The multiobjective Pareto front of renewable energy under uncertainty. (a) The triple-objective Pareto front. (b) The Pareto front of economic cost and battery cost.

TABLE 5: The multiobjective optimization interval of renewable energy under uncertainty.

\begin{tabular}{lccc}
\hline Fluctuation rate (\%) & Economic cost & Battery cost & CO $_{2}$ emission \\
\hline-10 & {$[2406.22,2560.66]$} & {$[108.81,175.44]$} & {$[959.48,1064.76]$} \\
+10 & {$[2211.60,2462.13]$} & {$[103.86,245.51]$} & {$[817.95,988.72]$} \\
-20 & {$[2506.30,2614.36]$} & {$[65.49,103.43]$} & {$[1031.78,1105.43]$} \\
+20 & {$[2209.75,2404.60]$} & {$[112.14,252.66]$} & {$[812.66,945.48]$} \\
-30 & {$[2506.30,2614.36]$} & {$[65.49,103.43]$} & {$[1031.78,1105.43]$} \\
+30 & {$[2209.75,2404.60]$} & {$[112.14,252.66]$} & {$[812.66,945.48]$} \\
\hline
\end{tabular}




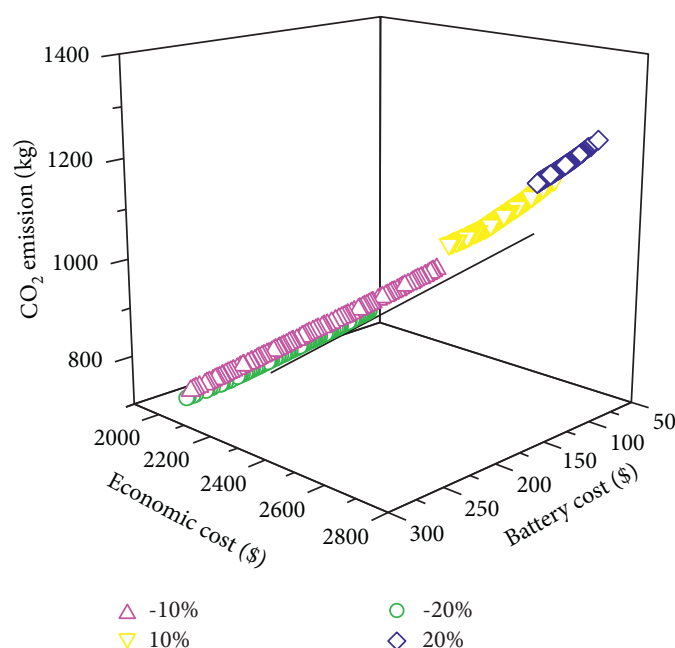

(a)

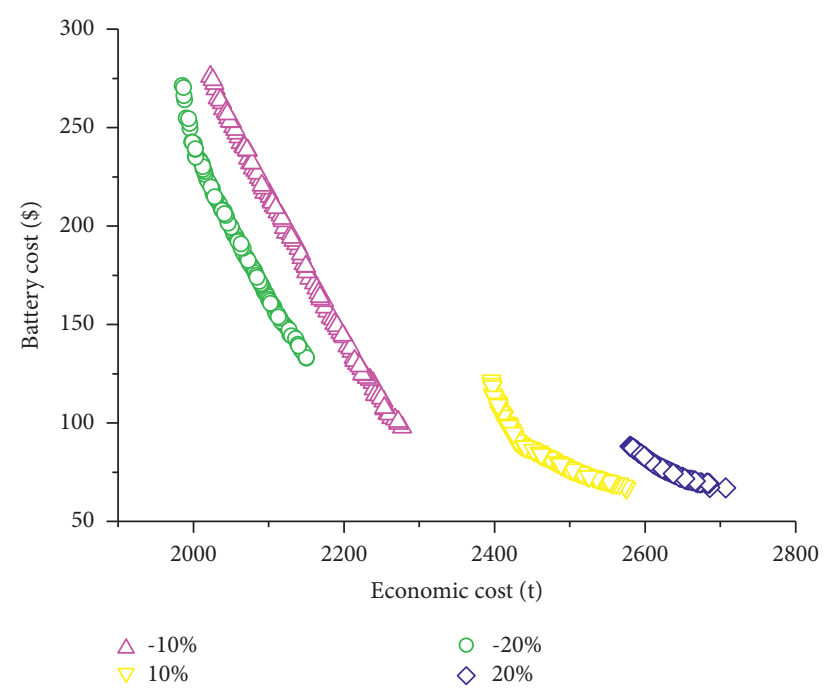

(b)

Figure 8: The multiobjective Pareto front of load under uncertainty. (a) The triple-objective Pareto front. (b) The Pareto front of economic cost and battery cost.

TABLE 6: The multiobjective optimization interval of load under uncertainty.

\begin{tabular}{lccc}
\hline Fluctuation rate $(\%)$ & Economic cost & Battery cost & CO $_{2}$ emission \\
\hline-10 & {$[2022.86,2277.26]$} & {$[97.70,276.01]$} & {$[735.66,919.92]$} \\
+10 & {$[2395.93,2575.24]$} & {$[66.76,121.43]$} & {$[1005.85,1135.71]$} \\
-20 & {$[1985.47,2150.34]$} & {$[132.87,271.25]$} & {$[708.60,828.00]$} \\
+20 & {$[2580.03,2706.92]$} & {$[66.96,88.14]$} & {$[1139.18,1231.07]$} \\
\hline
\end{tabular}

TABLE 7: Calculation time of the proposed approach.

\begin{tabular}{lccc}
\hline Scenarios & & Time (s) \\
& Minimum & Maximum & 12.86 \\
Average \\
\hline Deterministic optimization & 10.86 & 31.01 & 11.77 \\
Renewable energy under uncertainty & 28.79 & 30.16 & 29.93 \\
Load under uncertainty & 29.15 & 29.63 \\
\hline
\end{tabular}

Therefore, we can draw a conclusion: the computational efficiency of the proposed approach can meet the real-time requirements of the microgrid operation optimization.

\section{Conclusions}

With the increased penetration of renewable generation, the uncertainties caused by renewable generation and load have gained more and more attention in operation and energy management for an isolated microgrid. In this paper, an optimal dispatch model for island microgrid incorporating multiobjective operation optimization and interval uncertainties is proposed. The modelling process is easy to implement and the model has fewer parameters. The multiobjective interval optimization results can directly present the distribution interval of multiple objectives, which is convenient for operators to evaluate the influence caused by renewable generation and load uncertainties. A multiobjective optimization objective function to minimize the economic cost, battery cost, and pollutant emission of an island microgrid is established, in which the battery cost is regarded as a separate optimization objective. An improved multiobjective grey target decision-making method is put forward to realize the tradeoff between economic cost and battery cost. The computational efficiency of the proposed approach satisfies the real-time requirements of the microgrid operation optimization.

In the future work, we will use historical data of renewable resources to analyse correlations of their uncertainties and establish the correlation model of different uncertainties and also select the most suitable algorithm for solving the multiobjective optimization model based on interval uncertainty proposed in this paper by study the performance of different multiobjective optimization algorithms. This could further improve the optimal operation of microgrids and enhance the utilization of renewable energy. 


\section{Data Availability}

The data used to support the findings of this study are available from the corresponding author upon request.

\section{Conflicts of Interest}

The authors declare no conflicts of interest.

\section{Acknowledgments}

This work was financially supported by the National Key R\&D Program of China (supported by the Ministry of Science and Technology of PRC (no. 2016YFC0305001)) and the National Science and Technology Support Program (supported by the Ministry of Science and Technology of PRC (no. 2014BAC01B05)).

\section{References}

[1] S. Y. Ding, X. N. Lin, Z. Chen, Z. X. Wang, Z. Y. Zhang, and Z. T. Li, "A design and dispatch strategy of storage-hydrogencooling combined renewable energy absorption facility on rich resource island," Proceedings of the CSEE, vol. 39, no. 16, pp. 4659-4673, 2019.

[2] B. Zhao, D. M. Li, Z. J. Wu, X. S. Zhang, X. J. Wang, and Y. J. Tang, "Capacity optimal sizing of island microgrid clusters based on the target of $100 \%$ green energy power supply," Proceedings of the CSEE, vol. 41, no. 3, pp. 932-945, 2021.

[3] X. Y. Ding, W. Sun, G. P. Harrison, X. Lv, and Y. Weng, "Multi-objective optimization for an integrated renewable, power-to-gas and solid oxide fuel cell/gas turbine hybrid system in microgrid," Energy, vol. 213, Article ID 118804, 2020.

[4] Y. Li and F. Nejabatkhah, "Overview of control, integration and energy management of microgrids," Journal of Modern Power Systems and Clean Energy, vol. 2, no. 3, pp. 212-222, 2014.

[5] A. Ghaffari and A. Askarzadeh, "Design optimization of a hybrid system subject to reliability level and renewable energy penetration," Energy, vol. 193, Article ID 116754, 2020.

[6] J. Chen, C. S. Wang, B. Zhao, and X. S. Zhang, "Economic operation optimization of a stand-alone microgrid system considering characteristic of energy storage system," Automation of Electric Systems, vol. 36, no. 20, pp. 25-31, 2012.

[7] J. Liu, W. J. Wang, and G. P. Zhang, "Economic operation optimization of island microgrid with seawater desalination system," Electric Power Engineering Technology, vol. 38, no. 6, pp. 122-129, 2019.

[8] Y. Li, Z. Yang, D. Zhao, H. Lei, B. Cui, and S. Li, "Incorporating energy storage and user experience in isolated microgrid dispatch using a multi-objective model," IET Renewable Power Generation, vol. 13, no. 6, pp. 973-981, 2019.

[9] W. G. Zhao, Z. H. Ling, Y. Yang, X. W. Su, and J. Q. Zhao, "Multi-energy complementarity and optimization for island micro-energy network system," Proceedings of the CSU-EPSA, vol. 32, no. 8, pp. 54-61, 2020.

[10] E. Mayhorn, L. Xie, and K. Butler-Purry, "Mult-time scale coordination of distributed energy resources in isolated power systems," IEEE Transactions on Smart Grid, vol. 8, no. 2, pp. 998-1005, 2017.
[11] S. J. Ahn and S. I. Moon, "Economic scheduling of distributed generators in a microgrid considering various constraints," in Proceedings of the IEEE Power \& Energy Society General Meeting, Calgary, Canada, July 2009.

[12] W. Q. Li, T. Yu, and J. Q. Lin, "Environmental/economic optimal operation of microgrid considering randomness," Proceedings of the CSU-EPSA, vol. 27, no. 3, pp. 81-86, 2015.

[13] V. Miranda and P. S. Hang, "Economic dispatch model with fuzzy wind constraints and attitudes of dispatchers," IEEE Transactions on Power Systems, vol. 20, no. 4, pp. 2143-2145, 2005.

[14] B. Liang and J. Liao, "A fuzzy-optimization approach for generation scheduling with wind and solar energy systems," IEEE Transactions on Power Systems, vol. 22, no. 4, pp. 1665-1674, 2007.

[15] A. Zakariazadeh, S. Jadid, and P. Siano, "Smart microgrid energy and reserve scheduling with demand response using stochastic optimization," International Journal of Electrical Power \& Energy Systems, vol. 63, pp. 523-533, 2014.

[16] S. Talari, M. Yazdaninejad, and M. R. Haghifam, "Stochasticbased scheduling of the microgrid operation including wind turbines, photovoltaic cells, energy storages and responsive loads," IET Generation, Transmission \& Distribution, vol. 9, no. 12, pp. 1498-1509, 2015.

[17] Y. X. Liu, L. Guo, and C. S. Wang, "Economic dispatch of microgrid based on two stage robust optimization," Proceedings of the CSEE, vol. 38, no. 14, pp. 4013-4022, 2018.

[18] Y. Li, Z. Yang, G. Q. Li, D. Zhao, and W. Tian, "Optimal scheduling of an isolated microgrid with battery storage considering load and renewable generation uncertainties," IEEE Transactions on Industrial Electronics, vol. 66, no. 2, pp. 1565-1575, 2019.

[19] Y. Z. Li, P. Wang, H. B. Gooi, J. Ye, and L. Wu, "Multiobjective optimal dispatch of microgrid under uncertainties via interval optimization," IEEE Transactions on Power Systems, vol. 10, no. 2, pp. 2046-2058, 2019.

[20] S. X. Wang, D. Wang, and L. Han, "Interval linear programming method for day-ahead optimal economic dispatching of microgrid considering uncertainty," Automation of Electric Power Systems, vol. 38, no. 24, pp. 5-11, 2014.

[21] N. Mohsen, B. Martin, and T. Stefan, "Optimization of unit commitment and economic dispatch in microgrids based on genetic algorithm and mixed integer linear programming," Applied Energy, vol. 210, pp. 944-963, 2018.

[22] H. Hou, M. Y. Xue, Y. Xu et al., "Multi-objective economic dispatch of a microgrid considering electric vehicle and transferable load," Applied Energy, vol. 262, Article ID 114489, 2020.

[23] B. Zhao, X. S. Zhang, J. Chen, C. Wang, and Li Guo, "Operation optimization of standalone microgrids considering lifetime characteristics of battery energy storage system," IEEE Transactions on Sustainable Energy, vol. 4, no. 4, pp. 934-943, 2013.

[24] G. Niu, Y. Ji, P. K. Chen et al., "Optimal energy dispatching method for island microgrid with ocean power generation," Electric Power Construction, vol. 42, no. 6, pp. 96-104, 2021.

[25] N. P. Zhou and F. Wu, "Wind-wave and grey model based short-term output power prediction of wave energy generation system," Electric Power Automation Equipment, vol. 38, no. 5, pp. 58-63, 2018.

[26] B. Yang, W. B. Feng, and D. J. Yu, "Analysis on wind-wave relationship on north coastal waters of Jiangsu radial sand ridges," Journal of Waterway and Harbor, vol. 35, no. 6, pp. 578-581, 2014. 
[27] P. Li, D. Xu, Z. Zhou, and W.-J. Lee, "Stochastic optimal operation of microgrid based on chaotic binary particle swarm optimization," IEEE Transactions on Smart Grid, vol. 7, no. 1, pp. 66-73, 2016.

[28] C. Liu, X. Wang, and X. Wu, "A multi-layer dispatch theory of combined wind-storage systems considering optimization of battery units," Power System Technology, vol. 40, no. 10, pp. 3029-3037, 2016.

[29] B. L. Zhang, L. X. Hu, Y. Liu, J. L. Mao, and A. S. Zhou, "Shortterm scheduling model for microgrids with improved discrete particle swarm optimization," Power System Technology, vol. 40, no. 6, pp. 1717-1723, 2016, in Chinese.

[30] R. Dufo-López and J. Bernal-Agustín, "Multi-objective design of PV-wind-diesel-hydrogen-battery systems," Renewable Energy, vol. 33, no. 12, pp. 2559-2572, 2008.

[31] K. J. Qian, Y. Yuan, X. D. Shi, C. K. Zhou, and P. Ju, "Environmental benefits analysis of distributed generation," Proceedings of the CSEE, vol. 28, no. 29, pp. 11-15, 2008.

[32] X. R. Zhu, W. Y. Xie, and G. W. Lu, "Day-ahead scheduling of combined heating and power microgrid with the interval multi-objective linear programming," High Voltage Engineering, vol. 40, no. 1, pp. 1393-1409, 2021.

[33] K. Deb, A. Pratap, S. Agarwal, and T. Meyarivan, "A fast and elitist multiobjective genetic algorithm: NSGA-II," IEEE Transactions on Evolutionary Computation, vol. 6, no. 2, pp. 182-197, 2002.

[34] Q. Q. Wang, J. Zeng, J. F. Liu, J. L. Chen, and Z. G. Wang, “A distributed multi-objective optimization algorithm for resource-storage-load interaction of microgrid," Proceedings of the CSEE, vol. 40, no. 5, pp. 1421-1431, 2020.

[35] Z. X. Wang, Y. G. Dang, and H. Yang, "Improvements on decision method of grey target," Systems Engineering and Electronics, vol. 31, no. 11, pp. 2634-2636, 2009. 